\title{
Dental abnormalities in the red fox Vulpes vulpes from Poland
}

\author{
Elwira SZUMA
}

Szuma E. 1999. Dental abnormalities in the red fox Vulpes vulpes from Poland. Acta Theriologica 44: 393-412.

The sample of 1453 specimens of the red fox Vulpes vulpes (Linnaeus, 1758) from Poland was analysed from the point of view of the presence and frequency of congenital dental abnormalities. Deviations from the steady dental pattern were found in 196 specimens (56 females, 100 males and 40 specimens of unknown sex). Together 230 cases of anomalies were classified to eight different categories of dental abnormalities. The most frequent anomalies were: oligodonties (7.2\%; leaving out those of $\mathrm{M}_{3}-2.8 \%$ ). The frequencies of the remaining categories were the following: deviations from the typical shape of the tooth $-2.5 \%$, hypoplastic changes of the tooth enamel $-2.5 \%$, presence of extra roots $-2.0 \%$, polidonties $-2.0 \%$, irregularities in the position of the teeth $-1.9 \%$, partial split of the crown $-1.4 \%$, partial eruption of the teeth $-0.7 \%$. The frequency of the dental abnormalities was significantly higher $(p<0.05)$ in males $(15.7 \%)$ than females $(10.5 \%)$. Six out of eight categories of the dental abnormalities, ie: oligodonty, polidonty, partial split of the crown, partial eruption of the teeth, deviations from the typical shape of the tooth and irregularities in the position of the teeth, were insignificantly more frequent in males. Additional roots were found equally often among males as females, while enamel hypoplasias occurred insignificantly more frequently among females than among males. The examples of the dental anomalies observed in red fox indicated that in many cases they did not result from the influence of a single factor but they were the effect of a combined operation two or more factors of both genetic and environmental nature.

Mammal Research Institute, Polish Academy of Sciences, 17-230 Białowieża, Poland, e-mail: eszuma@bison.zbs.bialowieza.pl

Key words: Vulpes vulpes, dental anomalies, Poland

\section{Introduction}

Examples of different kinds of dental anomalies in the representatives of many mammal species were repeatedly reported in literature (eg Robinson 1979, Wolsan $1984 \mathrm{c}, \mathrm{d})$. However, in the majority of the papers the differentiation between the authentic developmental anomalies and the cases of extreme but still natural variation was missing. The very term 'anomaly' denotes an abnormality, deviation, or departure from the established norm. However, the clarity of the borders between the 'norm' and the starting point from which we could speak about an 'anomaly' have been rising a lot of controversies over a long time. Not infrequently was the same feature considered by some as an anomaly, whereas by others as the extreme expression of natural variation. 
Wolsan (1984b) divided the cases of congenital dental variations, or in other words, the departures from the typical number, shape and size of the teeth, into two groups. To the first group he counted the extreme variants of a given trait in a population, for example the absence of $\mathrm{P}^{2}$ in some individuals of Felis bengalensis (Glass and Todd 1977), or the absence of $\mathrm{P}^{1}$ and $\mathrm{P}_{1}$ in some specimens of Meles meles (Lüps 1990, Szuma 1994). The second group comprised purely of anomalies, ie cases of departures (resulting from an abnormal development) caused by a mutation or influence of environmental factors, eg the occurrence of connate incisors in dogs of Lakeland terrier strain (Hitchin and Morris 1966), or the cases of partial eruption of $\mathrm{C}^{1}$ in the mixed-breed dogs (Bittegeko et al. 1995). In spite of such a differentiation, it is not always possible to explain the formation mechanism and causes of some dental anomalies. Therefore, not every case can be classified to one of the two categories proposed above. In case of the red fox, the frequent absence of $\mathrm{M}_{3}$ is a controversial phenomenon. Many authors (eg Döcke 1959, Bree and Sinkeldam 1969, Lüps et al. 1972) see the feature of the congenital absence of $\mathrm{M}_{3}$ as one of many dental anomalies. However, taking into consideration the assumptions of Wolsan's conception (1984b) of differentiation between variation and anomaly, lack of $\mathrm{M}_{3}$ in the red fox dentition in the present paper was accepted as an extreme variant in the wide range of variations in this tooth. Therefore, the cases of the inborn absence of $\mathrm{M}_{3}$ were not included in the description of dental abnormalities. However, they were taken into account under the common consideration of oligodonty in order to obtain of a complete picture of this phenomenon in the red fox population from Poland.

In the provided below description of the specimens with anomalies a division into eight various categories of dental abnormalities was applied: (1) decrease of the number teeth - oligodonty, (2) increase of the number teeth - polidonty, (3) partial split of the tooth crown, (4) presence of extra roots and early stages of the separation of additional roots, (5) partial eruption, ie the presence in the permanent dentition one or more rarely, a greater number of the teeth which remained at some stage of eruption, (6) irregularities in position, such as: dislocations and rotations, (7) deviations from the typical shape of the teeth which were not connected with partial split of a crown and the phenomenon of formation or presence of extra roots, (8) hypoplastic changes in tooth enamel.

Hitherto the most circumstantial analysis of dental abnormalities in the red fox, supported by extensive material and enlarged by the comparisons of the frequencies of specified phenomena in free living foxes and farm foxes, was realised by Döcke (1959). In Döcke's study, the sample of the wild foxes were mainly specimens from Germany, but it also included foxes from Russia and other regions of Europe. Therefore, the results of the author's investigations are not convenient for the interpopulation comparisons of dental anomalies in the red fox. In papers by Bree and Sinkeldam (1969), Rantanen and Pulliainen (1970), Lüps et al. (1972) and Ansorge (1993) describing dental conditions of chosen populations of the red fox, the cases of some congenital and acquired dental anomalies are considered 
together. However, only inborn dental abnormalities give us a possibility to look into the course of the dental developmental process and verify conceivably the patterns and theories explaining the ontogeny of the heterodonty in mammals.

The aim of the present paper is to characterize the cases of the congenital dental abnormalities in the red foxes from Poland and the attempt to explain the etiology and ontogeny of particular categories, or even cases of dental deviations.

\section{Material}

From the common number of 1453 specimens of the red fox Vulpes vulpes (Linnaeus, 1758), 196 skulls revealing various dental abnormalities were selected. The material came from the collection of the Mammal Research Institute of the Polish Academy of Sciences in Białowieża (MRI, 959 skulls) and from the Institute of the Systematics and Evolution of Animals of the Polish Academy of Sciences in Cracow (ISEZ, 494 skulls). The foxes were gathered during the period between 1927 and 1996 from the territory of Poland.

The sample of 196 foxes included 56 females, 100 males and 40 individuals of undetermined sex. The examinations consisted in a scrupulous study of the dentition of each specimen, description of the observed congenital dental abnormalities, and creation of the photographic documentation in some chosen cases. Extensive list of particular cases of the dental abnormalities was not included in this paper. Readers interested in obtaining this list are pleased to contact the author.

\section{Results}

Out of 1453 examined specimens of the red fox from Poland, 196 individuals showed congenital deviations from the typical number, shape, size or position of the teeth.

In 230 cases of dental abnormalities found in 196 skulls, $20.9 \%$ were oligodonties. The fewest were cases of foxes with partial eruptions of teeth, ie $5.1 \%$. The percentage of the remaining categories of dental abnormalities varied from 10.2 to $18.4 \%$ (Table 1 ).

Table 1. Share of particular categories of dental abnormalities: $\%_{\mathrm{A}}$ in the sample of 196 skulls, $\%_{\mathrm{B}}$ in the examined population of foxes in Poland $(\mathrm{N}=1453) ; n$-number of specimens with a definite category of dental anomaly.

\begin{tabular}{lrrr}
\hline Category of anomaly & $n$ & $\%_{\mathrm{A}}$ & $\%_{\mathrm{B}}$ \\
\hline Oligodonty (including $\mathrm{M}_{3}$ ) & 104 & - & 7.2 \\
Oligodonty (excluding $\mathrm{M}_{3}$ ) & 41 & 20.9 & 2.8 \\
Polidonty & 29 & 14.8 & 2.0 \\
Partial split of a crown & 20 & 10.2 & 1.4 \\
Extra roots & 30 & 15.3 & 2.1 \\
Irregularities in position of teeth & 28 & 14.3 & 1.9 \\
Deviation from typical shape of a tooth & 36 & 18.4 & 2.5 \\
Enamel hypoplasias & 36 & 18.4 & 2.4 \\
Partial eruption & 10 & 5.1 & 0.7 \\
\hline
\end{tabular}


Table 2. The number and distribution of dental anomalies in the red fox dentition from Poland (the left- and righthanded anomalies together).

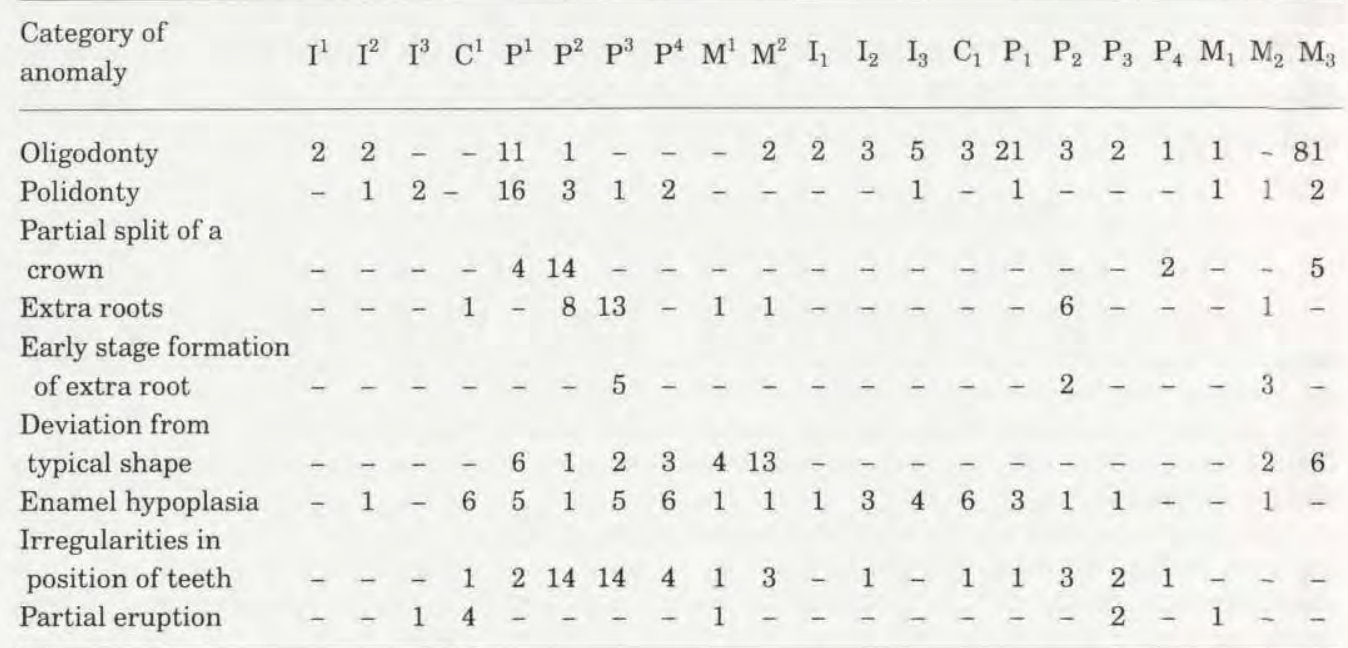

The phenomenon of congenital absence of one or more teeth, ie oligodonty, appears with the frequency of $7.2 \%$, excluding $\mathrm{M}_{3}$ showing the frequency of $2.8 \%$. Oligodonty is almost six times more often in the mandible than in the maxilla. If we leave the analysis of $\mathrm{M}_{3}$ aside, the rate changes into 2 to 1 (Table 2). $\mathrm{P}_{1}$ and $\mathrm{P}^{1}$ turned to be the most frequently absent teeth after $\mathrm{M}_{3} . \mathrm{P}_{1}$ was missing in 17 skulls, in four of them bilaterally and in the remaining thirteen - unilaterally. The oligodonty of $\mathrm{P}^{1}$ was bilateral in three specimens and unilateral in five. Moreover, the following data concerning oligodonty were noted: $\mathrm{I}_{3}(n=5), \mathrm{P}_{2}, \mathrm{I}_{2}, \mathrm{C}_{1}(n=3)$,

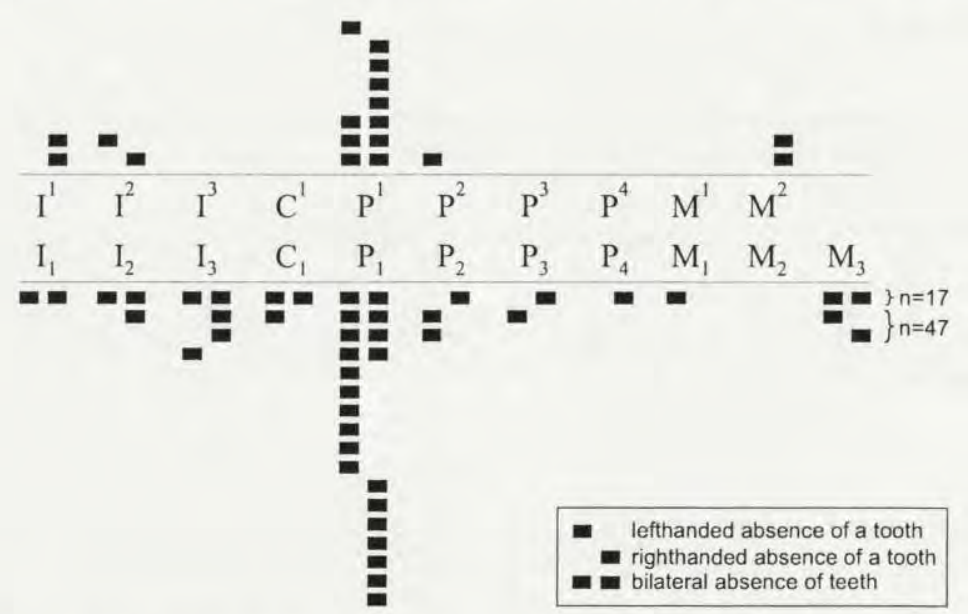

Fig. 1. Distribution of the cases of oligodonties in the dentition of the red fox from Poland. 


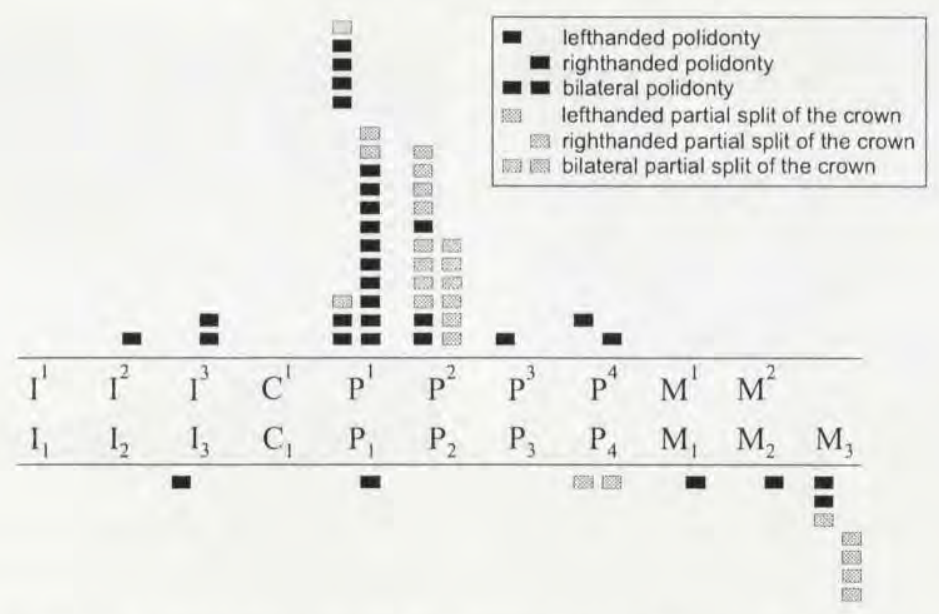

Fig. 2. Distribution of the cases of polidonties and partial split of a crown in the dentition of the red fox from Poland.

$\mathrm{I}^{1}, \mathrm{P}_{3}, \mathrm{M}^{2}, \mathrm{I}^{2}(n=2), \mathrm{I}_{1}, \mathrm{P}^{4}, \mathrm{M}_{1}(n=1)$. The inborn absence of teeth other than $\mathrm{M}_{3}$, $\mathrm{P}^{1}$ and $\mathrm{P}_{1}$ was most often unilateral (Table 2, Fig. 1).

Contrary to oligodonty is the phenomenon of polidonty, which consists in a bigger number of teeth by either the appearance of additional teeth resembling the teeth from the tooth row, or by the appearance of supernumerary teeth. Most often they are simple and cylindrical in shape. This enlargement in the tooth number was found in 29 red foxes. Polidonty is almost four times as frequent in the dentition of the upper jaw as in the one of the lower jaw. Polidonty occurs most often in the region of $\mathrm{P}^{1}$ and $\mathrm{P}^{2}$ (Table 2, Fig. 2). Additional $\mathrm{P}^{1}$ and $\mathrm{P}^{2}$ are usually very similar in shape and size to the proper premolars, and usually it is difficult to define which of the two is the additional one (Fig. 3 and 4). The supernumerary teeth differ from the neighbouring teeth from the row both in size and shape. In two specimens, the supernumerary teeth have got a heavily simplified, pillar-like shape. A supernumerary tooth of a complex structure of the crown and with two roots was found

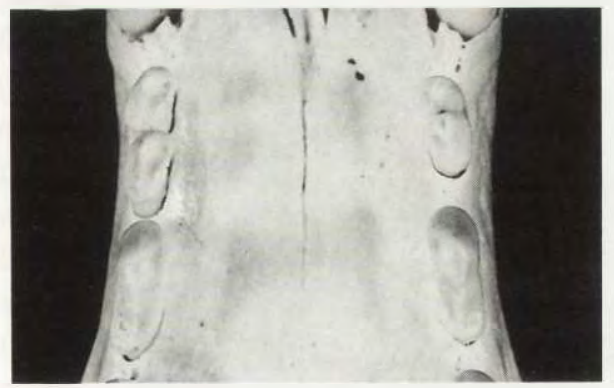

Fig. 3. Duplication of the right $\mathrm{P}^{1}$ and partial split of the crown of the left $\mathrm{P}^{\mathrm{P}}$ in red fox MRI 325.



Fig. 4. Polidonty within the left $\mathrm{P}^{2}$ in specimen ISEA $3389 / 67$. 


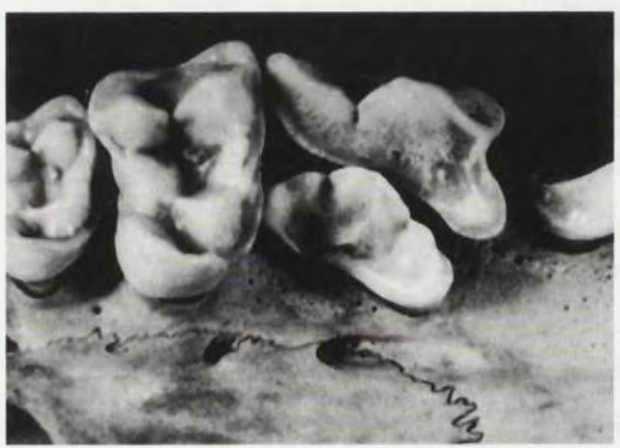

Fig. 5. Supernumerary tooth on the lingual side of the right, upper carnassial in specimen MRI 164841 .

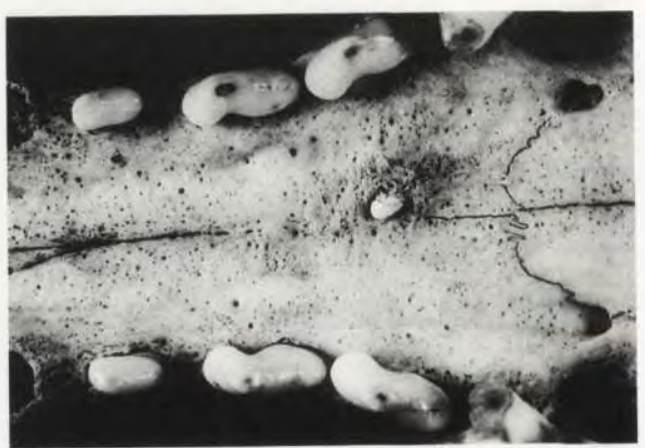

Fig. 6. Fragment of the tooth in the neighbourhood of palatal suture intermediate in specimen MRI 164951.

exceptionally near the upper carnassial of specimen MRI 164841 (Fig. 5). In the individual marked MRI 164951 (Fig. 6) a supernumerary tooth erupted out of the tooth row, closely to the intermediate palatal suture.

In three foxes the polidonty on one side of the upper tooth row was accompanied by bifurcation of the crown of the corresponding tooth in the row on the other side (Fig. 3). Partial split of the crown was observed mainly in $\mathrm{P}^{2}$ and also $\mathrm{P}^{1}$. In three cases split of the right $M_{3}$ crown and in one case split of the left $M_{3}$ crown were noted (Fig. 7). Also once a bilateral partial split of the $\mathrm{P}^{4}$ crown was registered (Table 2, Fig. 2).

Apart from the variations in the number of teeth in foxes, some variations in the number of tooth roots were observed. Extra roots were found in thirty individuals. Most often they were found on $\mathrm{P}^{2}, \mathrm{P}_{2}$ and $\mathrm{P}^{3}$ (Table 2). Except for these, presence of untypical supernumerary roots on the left $\mathrm{C}^{1}$, right $\mathrm{M}^{2}$, left and right $\mathrm{M}_{2}$, as well as the left $\mathrm{M}^{1}$ was registered. Additional roots on premolars occur in foxes both unilaterally and bilaterally. Such a root is usually situated medially in relation to the two proper ones. It can be found both on the lingual or buccal side of the tooth, and directly behind the eocone or eoconide (Fig. 8). Sometimes the appearance of an

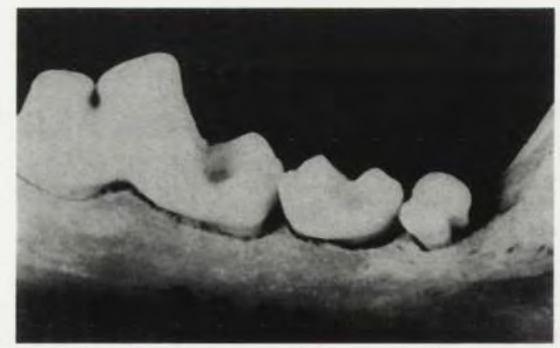

Fig. 7. Partial split of the crown of the right $\mathrm{M}_{3}$ in red fox ISEA 3298/67.

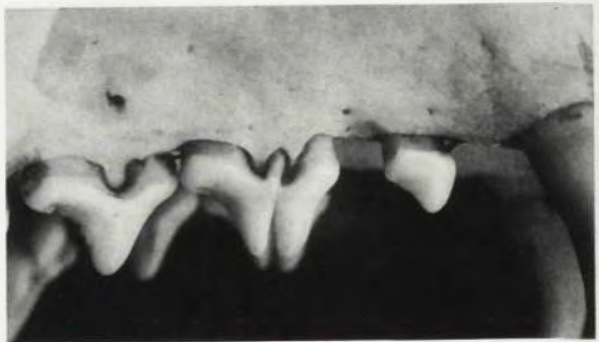

Fig. 8. Additional, third root in both $\mathrm{P}^{2}$ in red fox ISEA 3385/67 (right $\mathrm{P}^{2}$ from the buccal side). 


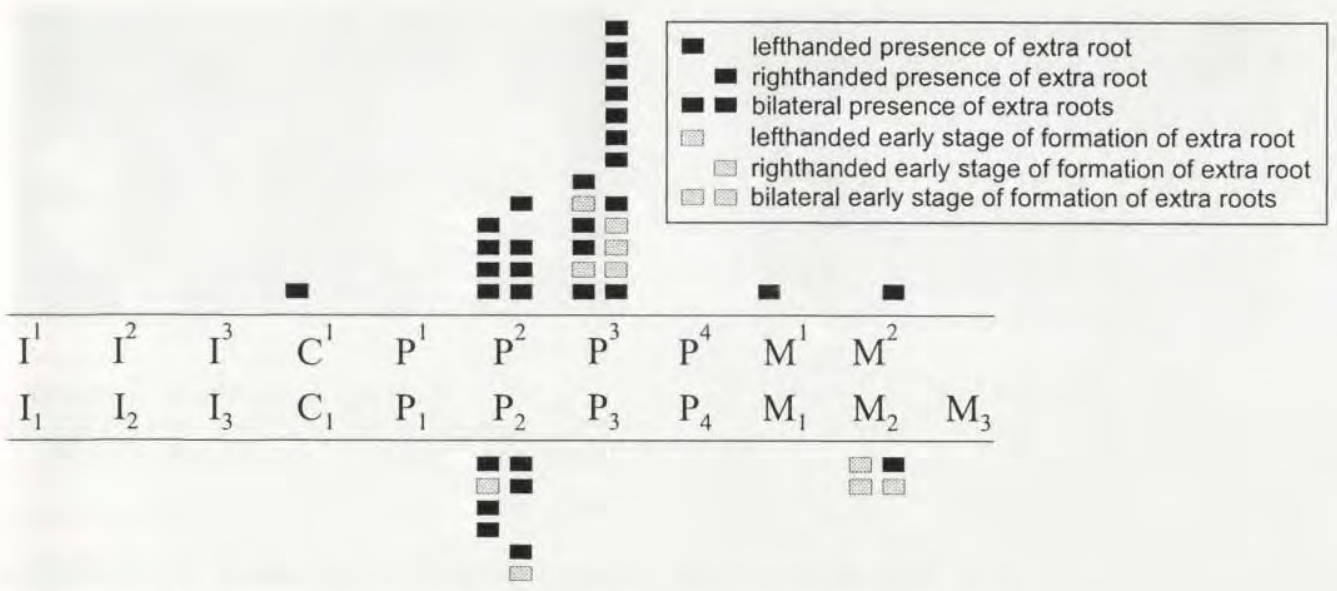

Fig. 9. Distribution of extra roots in the dentition of the red fox from Poland.

Fig. 10. Right $\mathrm{P}_{2}$ with three roots in specimen ISEA $3495 / 67$.

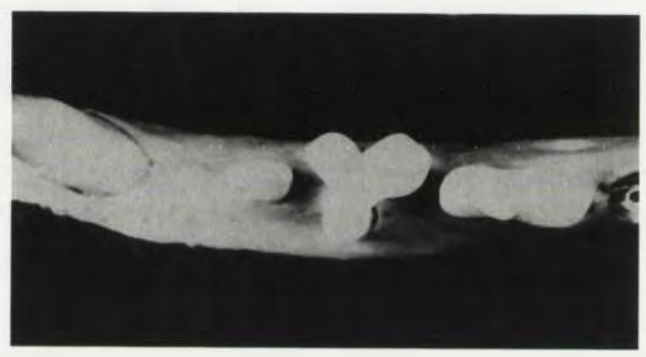

additional root on one side is followed by the beginning of the separation process of an additional root on the opposite side (Fig. 9). The presence of extra roots (Fig. 10) and early stages of the separation process usually result in a change in the outline of the tooth crown seen from above.

Apart from deformations of tooth shapes caused by incomplete crown splits, as well as irregularities in shape accompanied by changes in the number of roots, $2.5 \%$ individuals showed other, not related to the phenomena mentioned above, cases of deviations from the proper tooth shapes. These deformations consisted in a change of the crown outline (convexities, depressions, lack of the proper oval shape typical of a given family of teeth), faulty formation of the occlusal surface of the crown, presence of additional and incorrect structures (Fig. 11), reduction of the tooth size, as well as reduction of the number of roots (Fig. 12). These deviations occur almost four times more often in the maxilla than in the mandible. They concentrate mainly within the premolars and molars of the maxilla and molars of the mandible (Table 2).

In the dentition of the red foxes from Poland $2.4 \%$ specimens showed the enamel hypoplasias. These disturbances appeared the most often in the shape of transverse grooves on the smooth enamel surface. They were usually observed in singular, less 


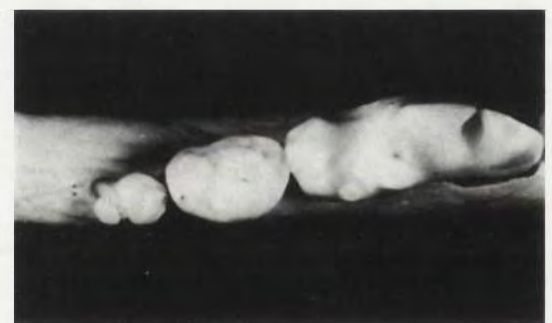

Fig. 11. Enamel pearl on the distal side of the neck of the left $\mathrm{M}_{3}$ in specimen MRI 62052.

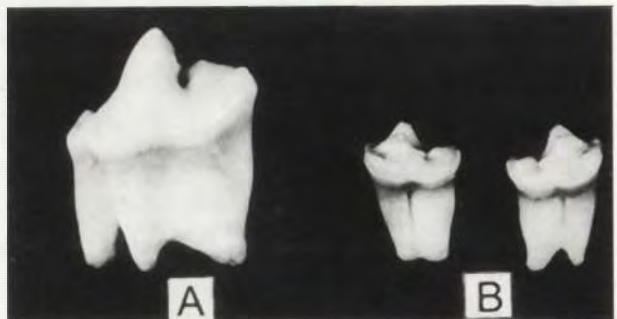

Fig. 12. Reduction of the number of roots: $\mathrm{A}$ on the right $\mathrm{P}^{4}$ in red fox MRI $165109, \mathrm{~B}$ - on the left and right $\mathrm{M}_{2}$ in red fox MRI 165195 .

frequently in two or three teeth in an individual dentition. Most hypoplasias occurred in the upper and lower incisors, lower premolars and upper molars (Table 2).

Irregularities in the position of teeth $(1.9 \%)$ mainly consist in dislocations within the tooth row (Fig. 13), deflections (Fig. 14) or minor rotations around a tooth axis. Exceptionally a 180-degree turn of the $\mathrm{C}^{1}$ in one specimen and a 90-degree turn of the $\mathrm{M}^{2}$ in another were observed. Irregularities in the position of teeth concentrate primarily within upper premolars $\left(\mathrm{P}^{2}, \mathrm{P}^{3}\right)$, less often in the lower premolar region, and occasionally on other teeth (Table 2).

In the permanent dentition of the examined foxes, ten cases of incomplete eruptions of teeth were registered. Five individuals had partial eruptions of one of the maxilla canines, two other foxes had unilaterally delayed eruptions of $\mathrm{P}_{3}$. The others were individual cases of incomplete eruptions of the right $M^{1}$, left $M_{1}$ and left $\mathrm{I}_{3}$ (Fig. 13; Table 2).

The frequency of dental abnormalities in males was considerably higher than that in females $\left(\chi^{2}=6.45 ; p<0.05\right)$. Out of 637 males, 100 individuals showed dental anomalies (15.7\%), whereas out of 535 females $-56(10.5 \%)$. In the sample of

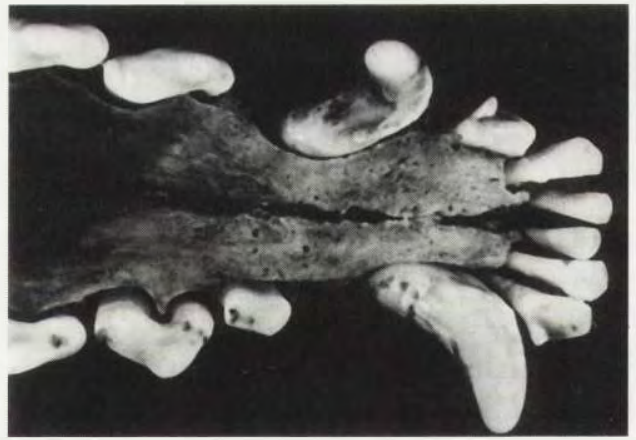

Fig. 13. Partial eruption of the $\mathrm{I}_{3}$, dislocation of the $\mathrm{C}_{1}$ and oligodonty of the $\mathrm{P}_{1}$ in the left mandibular tooth row in red fox MRI 165200

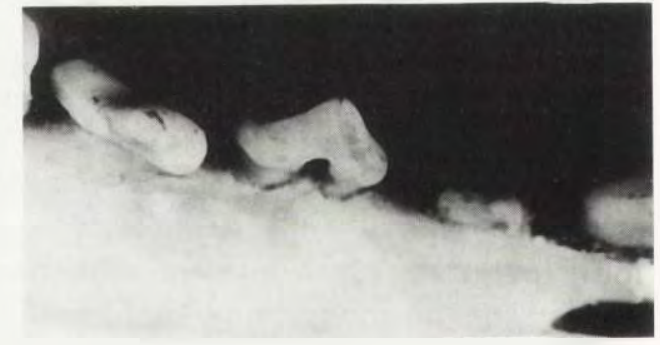

Fig. 14. Departure in more buccal direction of the crown of right $\mathrm{P}^{2}$ in red fox MRI 402. 
Table 3. Comparison of frequencies of dental anomalies in females $(n=535)$ and males $(n=637)$ of the red fox from Poland. $n_{f}\left(\%_{f}\right)$ - number (percentage) of females with a particular category of dental anomaly, $n_{\mathrm{m}}\left(\%_{\mathrm{m}}\right)$ - number (percentage) of males with a particular category of dental anomaly; ${ }^{*}-0.01<p<0.05$, lack of the asterisk with the $\chi^{2}$ coefficient marks $p>0.05$.

\begin{tabular}{lrrrrrr}
\hline Category of anomaly & $n_{\mathrm{f}}$ & $\%_{\mathrm{f}}$ & & $n_{\mathrm{m}}$ & $\%_{\mathrm{m}}$ & $\chi^{2}$ \\
\hline Oligoconty & 11 & 2.1 & $<$ & & & \\
Polidonty & 6 & 1.1 & $<$ & 12 & 2.7 & 0.24 \\
Partial split of a crown & 5 & 0.9 & $<$ & 12 & 1.9 & 2.85 \\
Extra roots & 11 & 2.1 & $\cong$ & 13 & 2.0 & 0,00 \\
Partial eruption & 1 & 0.2 & $<$ & 8 & 1.3 & 3.07 \\
Deviation from typical shape of a tooth & 11 & 2.1 & $<$ & 20 & 3.1 & 0.94 \\
Enamel hypoplasias & 16 & 3.0 & $>$ & 12 & 1.9 & 1.09 \\
Irregularities in position of teeth & 5 & 0.9 & $<16$ & 2.5 & 3.26 \\
Frequency of foxes with dental abnormalities & 56 & 10.5 & $<100$ & 15.7 & $6.45^{*}$ \\
\hline
\end{tabular}

specimens of undetermined sex, the level of anomalies was in the middle and accounted to $13.7 \%$. For eight categories of dental abnormalities, in six the frequency of deviations was higher for males than females. However, in none of these categories was the difference in deviations between sexes statistically significant $(p>0.05)$. The phenomenon of extra roots appeared equally often in females and males. The enamel degenerations were slightly more often in females $(p>0.05$; Table 3$)$.

\section{Discussion}

The registered instances of congenital dental abnormalities in the red foxes result from either the influence of different mechanisms in various stages of dental development or factors disturbing the development of correct and complete dental formala. The applied in this paper division into particular categories of dental abno:malities is based on the morphological similarity of the examined phenomena. None of the eight categories of dental deviations constitutes a group of anomalies resulting from identical processes in the same stages of ontogeny.

The most frequently observed oligodonty, may stem from the hereditarily condtioned lack of a tooth germ in the lamina, damage of a tooth germ and resorption, fusion of a tooth germ with a neighbouring one in the row, or from retention of the eruption process of a completely formed tooth, so-called dental impation. The factors responsible for such disturbances over the developmental process, and thus for the oligodonty process, may be both of genetic and environmental nature.

In the red foxes from Poland, the total frequency of all oligodonties reached $7.2 \%$ and was higher than the frequency of specimens with the inborn absence of one tooth or teeth observed by Ansorge (1993) in the red fox population from 
Oberlausitz $(n=704)$. Earlier investigations by Bree and Sinkeldam (1969) showed that this phenomenon was considerably more frequent in the population of foxes from Western Europe.

In the foxes studied, the most often missing teeth are $\mathrm{M}_{3}$ (4.5\%), then $\mathrm{P}_{1}(1.2 \%)$ and $\mathrm{P}^{1}(0.6 \%)$. Singular specimens with missing $\mathrm{I}^{1}, \mathrm{I}_{1}, \mathrm{I}^{2}, \mathrm{I}_{2}, \mathrm{I}_{3}, \mathrm{C}_{1}, \mathrm{P}_{2}, \mathrm{P}_{3}, \mathrm{P}_{4}, \mathrm{M}_{1}$, and $\mathrm{M}^{2}$ were noted too. A similar sequence of oligodonty frequencies in particular tooth families were observed in a sample of free living foxes (mainly individuals from the territory of Germany) by Döcke (1959). A high frequency of missing $\mathrm{M}_{3}$ and $\mathrm{P}_{1}$ was registered in the population of foxes from northern Lapland $(n=75)$ (Rantanen and Pulliainen 1970). Out of 291 foxes from the south of Sweden, as many as $10 \%$ specimens showed lack of $\mathrm{M}_{3}$ (Reinwaldt 1962), whereas in foxes from Western Europe ( $n=293$ ) the frequency of missing $\mathrm{M}_{3}$ equalled $10.9 \%$, and the one of missing $\mathrm{P}_{1}-1.4 \%$ (Bree and Sinkeldam 1969). High, in comparison to other teeth, frequency of the congenital absence of $\mathrm{M}_{3}, \mathrm{P}_{1}$ and $\mathrm{P}^{1}$ resulted from their peripheral position in the buccal tooth row. The presence of numerous bilateral oligodonties of the $\mathrm{M}_{3}(n=17)$ and $\mathrm{P}_{1}$ and $\mathrm{P}^{1}(n=7)$ suggests a hereditary character of this phenomenon. Moreover, from the research in farm foxes Döcke (1959) concludes that the feature of congenital absence of $M_{3}$ is inherited in the recessive way, and the growth of inbreeding in the population raises the frequency of oligodonties of the last molar.

The origin of other oligodonties is less clear and more complex. The noted instance of lack of all the lower incisors, $\mathrm{C}_{1}, \mathrm{P}_{1}$, left $\mathrm{P}_{2}$ and left $\mathrm{M}_{1}$ in the red fox MRI 2713 (Fig. 15) most probably is a result of a disease suffered in the period of dental development, and connected with an infection of the bone tissue of the mandible.

It is not a simple task to determine whether the cases of unilateral oligodonties of $\mathrm{I}^{1}, \mathrm{I}^{2}, \mathrm{I}_{2}, \mathrm{I}_{3}$ in the examined population of foxes are a result of a fusion of a tooth germ with the neighbouring tooth in the row, a result of a mechanical damage to

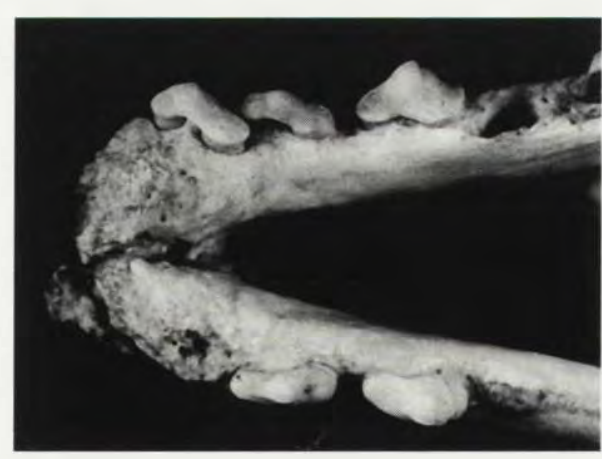

Fig. 15. Oligodonty of incisors and anterior premolars in the mandible in red fox MRI 2713. the germ in the developmental period and its aplasia, or a result of a restrained eruption of the tooth because of lost space in the tooth row. According to Wolsan (1984c), such ontogenetic mechanisms as no formation of the germ in the dental lamina and fusion of a tooth germ are responsible for the congenital absence of an incisor or incisors in the dentition of carnivora.

In literature one can find examples of oligodonties of incisors which are accompanied by changes in the morphology of the neighbouring teeth. On many occasions these changes are keys which enable to 
explain the etiology of the observed irregularities. Van Gelder and McLaughin (1961) describe a case of oligodonty of the right incisor in Mephitis mephitis in which there is one big incisor with a longitudinally split crown in the regular location of $\mathrm{I}^{1}$ and $\mathrm{I}^{2}$. This phenomenon is most probably a result of an incomplete fusion of germs. Similar cases were noted in the pine marten Martes martes by Wolsan (1984a). This author found two other instances of incisor oligodonties in pine martens with no changes in the neighbouring teeth. Berkovitz and Thomson (1973) suggest that fusion of two neighbouring tooth germs in a very early stage of dental development should not cause any enlargement of the tooth created in this way.

The incisor oligodonties observed in the red fox from Poland are not accompanied by any significant changes in the morphology of the neighbouring teeth. Therefore, the absence of the right $\mathrm{I}^{1}$ in two foxes from this material might result from a very early fusion of the right $\mathrm{I}^{1}$ germ with the next $\mathrm{I}^{2}$ one, so no enlargement of the $\mathrm{I}^{2}$ dimensions occurred, or from a damage to the germ and delayed tooth development. Oligodonty of the right $\mathrm{I}^{2}$ in the other specimen was not accompanied by traces of changes in the morphology or arrangement of the neighbouring teeth. This allows to assume that the basis for this phenomenon is anologous to the case of the right $\mathrm{I}^{1}$ absence. The some cases of the incisor oligodonties observed in this sample may result from a loss of accessible space and an eruption halt or a damage to germs of these teeth during their development.

In one case, congenital lack of the left $\mathrm{C}_{1}$ was observed. The development of this tooth had most probably been halted still before the process of eruption began, so there are no traces of the left $\mathrm{C}_{1}$ presence in the mandible. Dental impaction and dentition changes, such as: hypoplasia of the dental tissues, partial eruption of teeth or oligodonty in dogs, are frequently the results of canine distemper infection suffered in the pupil period (Bodingbauer 1960, Bittegeko et al. 1995). As among the free living populations of foxes cases of this disease are also observed (López-Peña et al. 1994), one can conclude that this is one of the factors responsible for some cases of oligodonties or other dental abnormalities. Dental anomalies in dogs, caused by canine distemper infection, are mainly observed on canines and premolars (Bodingbauer 1960, Bittegeko et al. 1995). Also in the red foxes from Poland deviations concentrate most often within canines and premolars (Szuma 1997). Apart from a single instance of canine oligodonty, three foxes with unilateral lack of $\mathrm{P}_{2}$ were found, as well as two foxes with unilateral oligodonty of $\mathrm{P}_{3}$ and one with the right $\mathrm{P}_{4}$ missing.

Tro cases of unilateral oligodonties of $\mathrm{M}^{2}$ in red foxes from this study probably are symptoms of the process of shortening of the molarization field in the upper jaw. This phenomenon occurs very infrequently in foxes, however among some canides, eg the American genus Speothos sp., it is quite common (Van Valen 1964). Occasionally the phenomenon of elongation of the molarization field is also observed both in the upper and lower jaw. In the red foxes from Poland not a single case of an additional $\mathrm{M}^{3}$ was noted, although two instances of unilateral presence of 
$\mathrm{M}_{4}$ and five individuals with partial split of the crown of $\mathrm{M}_{3}$ were registered. Döcke (1959) observed unilateral presence of $\mathrm{M}^{3}$ in two foxes, whereas Bree and Sinkeldam (1969) found two specimens with additional $\mathrm{M}_{4}$ in their sample of foxes from Western Europe. Ansorge (1993) indicates that one fifth of polidonties noted by him in the dentition of foxes from Oberlausitz are duplications of $\mathrm{M}_{3}$.

Occurrence of $\mathrm{M}^{3}$ and $\mathrm{M}_{4}$ is a frequent phenomenon among coyotes Canis latrans frustror (Paradiso 1966), and a totally common one in otocyons Otocyon megalotis (Guilday 1962, Van Valen 1964). The appearance of additional molars at the distal end of the buccal tooth row is genetically conditioned both in otocyons and in coyotes. Occasionally the appearance of additional extreme molars in the red fox is untypical and inconsistent with the current tendency to shorten the buccal tooth row in this species. The presence of a cylindrical and simple in shape $\mathrm{M}_{4}$ in the specimen ISEA $3458 / 67$ (Fig. 16) makes that the preceding $\mathrm{M}_{3}$ is larger than usually and possesses two roots. Already Van Valen (1962) indicated that the presence of additional last molars in the row was connected with a simultaneous enlargement and more complex shape of the occlusal surface of the crown of the next to the last molar. The additional last molar is probably a result of the appearance of an additional forth tooth germ in the dental lamina. The registered cases of unilateral partial split of the crown of $\mathrm{M}_{3}$ are a sign of an incomplete division of a tooth germ in an early stage of development, or an incomplete fusion of two tooth germs, ie the proper $\mathrm{M}_{3}$ and the additional $\mathrm{M}_{4}$.

Partial and complete duplications of $\mathrm{P}^{1}$ and $\mathrm{P}^{2}$ are more frequent than polidonties on $\mathrm{M}_{3}$. Complete duplications of teeth are more typical of $\mathrm{P}^{1}$, while partial split of the crown most often is observed on $\mathrm{P}^{2}$. Majority of doubled $\mathrm{P}^{1}$ submit to the proper for the buccal tooth row gradient of size and shape. In some both $\mathrm{P}^{1}$ are simple in structure and with singular roots, but almost always $\mathrm{P}^{1}$ is located closer to $\mathrm{P}^{2}$ and is a little bigger than $\mathrm{P}^{1}$ lying on the edge of the premolar row. With the phenomenon of $\mathrm{P}^{1}$ duplication and, a little more rarely, $\mathrm{P}^{2}$ doubling, the phenomenon of partial split of the tooth crown is closely connected. First of all, it is caused by the fact that in some individuals these two phenomena occur



Fig. 16. Additional, right molar in the left dental bone in red fox ISEA 3458/67. simultaneously. Secondly, these phenomena concentrate within the same dental region, and their genetically conditioned presence is a result of similar mechanisms. The presence of an extra $\mathrm{P}^{1}$ or $\mathrm{P}^{2}$ may stem both from the formation of additional tooth germs in the dental lamina and from a split of a singular germ into two. An experiment carried out on rabbit embryos by Glasstone (1952) proved that from a molar cut in two along the bucco-lingual axis, two separate teeth of the correct shape of the crown formed. Reports 
on numerous observations of tooth germ fusions during dental development (eg Miles 1954, Berkovitz 1968) indicate that polidonty often results from an additional tooth germ formation. In the intervals between neighbouring germs, external enamel epithelium fits closely to the dental lamina. In further stages of development both these layers undergo disjunction and thus the unity between the two developing teeth is destroyed. However, if the disjunction of the external enamel epithelium from the dental lamina takes place earlier, cells of the inner enamel epithelium begin to find their way between the two layers and a fusion of the two tooth germs occurs (Hitchin and Morris 1966).

In the spacious material about red foxes one can go through almost all the variants of the process of a tooth germ fusion, ie from teeth clinging to each other because of being connected by enamel to singular premolars with common pulp and dentine, and with a heardly visible fissure on the apex of the tooth crown. The advancement in the process of a tooth germ fusion visible in permanent dentition of foxes is probably dependent upon the time in which the separation of the external enamel epithelium from the dental lamina begins. The earlier the separation of the external layer of enamel epithelium from the dental lamina starts, the higher the chance of a complete fusion of a tooth germs is.

Cases of additional teeth and partially divided crowns within incisors have been observed in representatives of merely all the contemporary families of carnivora (Wolsan 1984c). In developing deciduous dentition of ferrets and polecat-ferrets, germs of eight upper incisors were formed quite commonly. Later many times in the permanent dentition of these animals the presence of an additional incisor on one side of the maxilla, or a dichotomy of the crown's apex or even of the whole crown of one of the incisors were observed (Bateman 1970). This author suggests that the reason for the appearance of additional incisors in both forms of the polecat was the presence of more than six functional incisors in the maxilla in the evolutionary past of these animals.

The phenomenon of bifurcation of the crown of maxilla incisors has not been observed in foxes but three cases of polidonties in this dental region have. The comparative studies by Döcke (1959) proved that polidonty within incisors was an equally rare anomaly among free living foxes as among farm foxes of a higher inbreeding index.

Bateman (1970) shows that within the mandible incisors in Mustela there sometimes occur small changes in the tooth arrangement although their number invariably remains six. However, an instance of bifurcation of the right $\mathrm{I}_{2}$ crown in ermine Mustela erminea is known (Wolsan 1984e). From among about 1,500 foxes in this study, merely one individual MRI 165159 (Fig. 17) had four incisors in the left half of the mandible. Because of no room in the row, the

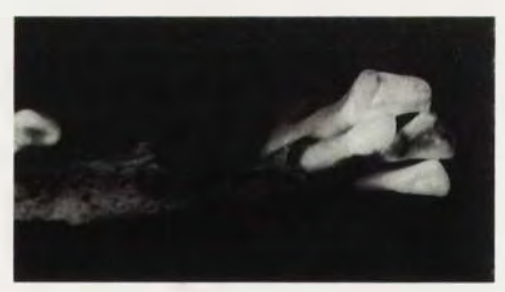

Fig. 17. Additional incisor on the lingual side of the left incisors row in the mandible of the red fox MRI 165159. 
supernumerary tooth was outside it. Its lingual position, size and different shape exclude the possibility that this supernumerary incisor is an extant deciduous tooth. The supernumerary incisor in specimen MRI 165159 (Fig. 17), as well as supernumerary teeth in two other foxes from this study are probably effects of some disturbances taking place during the dentition development process. The appearance of small cylindrical teeth may be caused by a split of some tissue fragment from the proper tooth germ, and a subsequent formation of a supernumerary tooth.

A different kind of a supernumerary tooth is placed parallelly to the right $\mathrm{P}^{4}$ on the lingual side of the row in the male marked MRI 164841 (Fig. 5). Neither size nor shape of the tooth resemble any of the proper teeth from the row. This evidence seems to prove that this tooth is a totally new structure which has appeared as a result of a mutation or disturbance in the genetic control. Similar cases of polidonty within the carnassial of the upper jaw were noted by Pavlinov (1975) in three individuals of Alopex lagopus.

However, the most unclear case of polidonty was the presence of tooth remains in the area of the intermediate palatal suture in the red fox MRI 164951 (Fig. 6). This tooth perhaps appeared there because of a remote, untypical in direction, translocation of a tissue fragment previously split from the dental lamina.

Apart from deviations from the correct number of teeth, $2.1 \%$ examined foxes show abnormalities in the number of roots. In the permanent dentition of this predator, all incisors and canines have singular roots; $\mathrm{P}^{1}, \mathrm{P}_{1}, \mathrm{M}_{3}$ have most often also one root which sometimes is partially divided, so occasionally these teeth may have two roots; $\mathrm{P}^{2}, \mathrm{P}^{3}, \mathrm{P}_{2}, \mathrm{P}_{3}, \mathrm{P}_{4}, \mathrm{M}_{1}$ and $\mathrm{M}_{2}$ properly have two roots; and $\mathrm{P}_{4}, \mathrm{M}^{1}$ and $\mathrm{M}^{2}$ possess three roots.

Additional roots appear most often on $\mathrm{P}^{3}, \mathrm{P}^{2}$ and $\mathrm{P}_{2}$. Out of 21 specimens with extra roots on premolars, this phenomenon occurred in five, either symmetrically on both sides of the maxilla $(n=4)$ or on both sides of the mandible $(n=1)$. Moreover, in three instances the presence of an additional root on a tooth on one side of the mandible or maxilla was accompanied by a halted at some stage process of separation of the third root on the corresponding tooth on the other side. Cases of bilateral appearance of additional roots on premolars, as well as a strong concentration of this feature within $\mathrm{P}^{2}$ and $\mathrm{P}^{3}$ seem to testify to a genetic basis of this phenomenon. For the beginning of the process of separation of an additional root, visible in the form of a convexity in the outline of a premolar's crown, as well as for the presence of the fully developed third root responsible are rare, but still present in the gene pool of this species, genes, which probably appeared much more frequently in the past. This supposition seems to be confirmed by the fact that such additional roots are found on premolars of many species of canides, eg in the red fox Vulpes vulpes on $\mathrm{P}^{2}, \mathrm{P}^{3}, \mathrm{P}_{2}$ (Döcke 1959, Lüps et al. 1972, Lüps 1974, Herán 1987), in the wolf Canis lupus on $\mathrm{P}^{3}$, $\mathrm{P}_{4}$ (Herán 1987), in the arctic fox Alopex lagopus on $\mathrm{P}^{3}$ (Pavlinov 1975).

Supernumerary, abnormal roots have been noted on the left $C^{1}$, left $M^{1}$ and right $\mathrm{M}^{2}$. The case of the supernumerary root on the left $\mathrm{C}^{1}$ could result from 
disturbances in the ontogenetic development of the tooth. This is also indicated by some degenerative changes visible on the enamel of this canine. The existence of an abnormal root on the right $\mathrm{M}^{2}$ in one fox from this study is accompanied by the presence of an additional tubercle on the buccal side of the cingulum. A similar phenomenon was observed in two different foxes by Döcke (1959) and Pavlinov (1975).

Additional roots on the molars in two other foxes from Poland did not influence the crown shape of these teeth. In about one third of the examined by me foxes, the molars were loosly set in the alveoli and accessible to be seen in full. Therefore, no one can be sure if these three specimens are the only individuals in the sample with additional molar roots.

Presence of additional roots and partial split of the crown are sometimes accompanied by serious disturbances in the crown shape. Instances of crown deformations induced by other factors than the phenomena were found in 36 foxes from Poland. The cases of convexities in the crown outline of the left or right $\mathrm{P}^{1}$, presence of an enamel lamina along the crown and root of the right $\mathrm{P}^{1}$, as well as reduction of the size and shape of the left $\mathrm{P}^{2}$ most probably are results of a sudden mutation or disturbances in the genetic control of the development. In four foxes deformations of the occlusal surface of the right $\mathrm{M}^{1}$ were observed. The crown of the right $\mathrm{M}^{1}$ in one specimen, except the shape irregularity, showed degeneration of enamel formation. It seems that in two other foxes, the deformations stem from an infection or some trauma which caused local disturbances in the development of both singular teeth.

In the examined foxes, deviations from the typical shape and size are the most frequently observed phenomena on $\mathrm{M}^{2}$. They consist mainly in incorrect formation of the occlusal surface of the crown, in reduction of a tooth size, as well as in bilateral reduction of the root number on this molar. Disturbances in the size and shape of this molar seem to be symptoms of demolarization. The cases of analogous abnormalities of the $\mathrm{M}^{2}$ were described in three foxes and in one arctic fox by Pavlinov (1975). This author stated that anomalies of the $\mathrm{M}^{2}$, both in the representatives of genus Vulpes and Alopex, were most probably a sign of an evolutionary process taking place in their dentition and consisting in a shortening of the tooth row from the back.

$\mathrm{M}_{3}$ is the next tooth as far as the frequency of deviations from the correct shape in the red fox from Poland is concerned. The deformations of the $\mathrm{M}_{3}$ crown consist primarily in the presence of inborn unnatural grooves or depression in the oval crown outline. The utmost, and thus not very stable, position of $\mathrm{M}_{3}$ in the buccal tooth row most probably makes that this tooth is subject to weakened genetic control during its development. This sets convenient conditions for more frequent presence of irregular $\mathrm{M}_{3}$, or congenital absence of this tooth.

Also three cases of unilateral presence of an enamel pearl (= enameloma) were noted on $\mathrm{M}_{3}$. So far sporadical cases of enamel pearl have been observed only in human dentition (eg Łepkowski and Stach 1907, Hitchin 1962, 1971, Hillson 1986, Cawson 1991). The appearance of an enamel pearl, ie a simpler form of a tooth 
neoplasm, odontoma compositum, may be genetically conditioned or caused by disturbances or a change in the genetic control during tooth development (Hitchin 1962). Although enameloma is a rare anomaly, often bilateral discoveries of enamel nodules in human dentition suggest hereditary conditioning of this phenomenon (Hitchin 1971). In case of the red fox, the unilateral presence of an enamel pearl does not confirm Hitchin's hypothesis. However, a small number of observed cases, as well as lack of information about the presence or absence of this kind of irregularity in animals related to the species mentioned above, do not allow to reject it. The formation of enamel nodules on $\mathrm{M}_{3}$ could also be caused by other than genetic factors, such as: damage to a tooth germ before the 'cup' stage of its development, infection during prenatal development (Hitchin 1971) and shortage of vitamin A in the diet (Burn et al. 1937 in Hitchin 1971).

Apart from deformations of a tooth shape and size in the red foxes from Poland, numerous cases ( $n=36$ ) of degenerations of tooth enamel were observed. It seems that this phenomenon has not been investigated at all so far, neither in free living nor captured populations of the red fox. Enamel hypoplasia is created as a result of a sudden break in the activity of ameloblasts during the development of a tooth (Goodman et al. 1980). It has been stated that either systemic disorders occurring during the dentition development (eg genetic diseases, inborn infections, mineral and vitamin shortages, severe disturbances of metabolism, etc.) or local factors (eg infections, stress, inflammatory processes appearing in the tooth germ neighbourhood, mechanical damages on the tooth germs) are sources of enamel deformations in humans (Cawson 1991, Bittegeko et al. 1995, Gawor 1995). Systemic disturbances most often cause disruptions in the enamel growth in all teeth, whereas enamel hypoplasias in singular teeth in the dentition result from the influence of local factors.

The registered instances of enamel depressions in foxes from this study concerned singular, more rarely several, teeth in the dentition, so they were effects of local factors. Anomalies in enamel formation were observed primarily on canines and premolars. In Tanzanian tropical mixed-breed dogs Canis familiaris enamel hypoplastic changes concentrate mostly around canines (Bittegeko et al. 1995). These authors indicate that those disturbances result from canine distemper infections suffered at a puppy age. It seems that the same illness in some cases could contribute to enamel growth gaps in the dentition of foxes. Singular enamel anomalies within premolars may result from both a viral infection and some other local factors. The probability of a mechanical damage or an inflammatory process in the germ neighbourhood is similar for all tooth positions, whereas severe stress causes enamel growth disruptions on these teeth which at a given moment are in the most intense stage of growth or enamel mineralization.

Irregularities in the position of teeth were noted in $1.9 \%$ of the examined foxes. They concerned mainly $\mathrm{P}^{2}$ and $\mathrm{P}^{3}$, and consisted in slight dislocations of teeth within the tooth row, minor departures from the stable positions or rotations. In some instances the position anomalies were caused by presence of additional or supernumerary teeth in the row, shortening of the whole tooth row and thus an 
irregular crowding of teeth, inborn absence or a very early loss of neighbouring teeth, or partial eruption of the preceding tooth.

In the dentition of specimen MRI 2713 (Fig. 15) three categories of anomalies have been found, viz. polidonty, oligodonty and irregularities in the position of the teeth. That fox suffered from degenerative changes within the anterior part of the mandible and underdevelopment of the mandible. These malformations could be effects of a disturbed developmental process caused by a severe viral infection suffered by the animal at its puppy age. This is indicated also by the crowding of premolars in the maxilla and the oblique position of the $\mathrm{P}_{2}$ and $\mathrm{P}_{3}$ in relation to the longitudinal axis of the tooth row.

In the majority specimens, the irregularities in position considered singular teeth, including premolars. Sporadically deviations were noted on incisors, and on two occasions strong rotations of the $\mathrm{M}^{2}$ were observed.

Döcke (1959), studying analogical kinds of tooth position anomalies in a sample of free living foxes, found frequencies of the occurring rotations $-2.2 \%$, departures $-1.6 \%$, and dislocations $-1.3 \%$. The overall frequency of irregularities in position registered for the red fox in Poland was lower than the one observed by Döcke in foxes from the territory of Germany and other parts of Europe. However, it seems that this difference is not a result of a naturally increased variation in tooth arrangement in wild foxes from Döcke's sample but a result of a more determined counting of all, even very minor, position asymmetries as tooth anomalies.

Partial eruption has been a completely ignored irregularity in the investigations so far. This phenomenon is the most rarely observed category of dental abnormalities in the red fox from Poland $-0.7 \%$. In all the registered cases, partial eruption concerned singular teeth. Three fourths of these cases were incomplete eruptions of canines and premolars. As it has been noticed before, concentration of such deviations as: hypoplastic changes of the enamel, oligodonty, and partial eruption around canines, in the anterior part of the premolar row, may indicate that a considerable part of disturbances are results of viral infections suffered in an early period of development. At that time the weakened system is more prone to any bacterial infection. The presence of an inflammatory focus in the vicinity of a developing tooth may cause temporary disruptions in the development, entirely delayed development or eruption, or even a destruction of the tooth germ. Local retention of the process of eruption may be also a result of the restraining impact of such factors as: long-term preservation of a milk tooth, premature loss of a milk tooth and a blockade of the space by the neighbouring teeth, appearance of additional teeth, cysts, abscesses or dental tumors.

Within the population of the red fox from Poland, a considerable dependence between the frequency of dental irregularities and sex was found. Out of the eight selected categories of dental anomalies, in six the numbers of males with irregularities were insignificantly higher than the ones of females. Extra roots were equally often among females and males, whereas enamel hypoplasias occurred insignificantly statistically more frequently in females than in males. 
The earlier reports on differences in the frequency of dental anomalies between individuals of both sexes in foxes or other predators concerned only some deviation categories. Buchalczyk et al. (1981) inform that a higher number of teeth in the dentition of Canis lupus is considerably more often in males than females. Contrary to the above, no significant differences in the frequency of oligo- and polidonties between individuals of both sexes were found by Asahi and Mori (1980) in the population of Nyctereutes procyonoides in the western part of Japan, and Ruprecht (1978) in the population of Mustela putorius from Poland. Ruprecht (1978) points at a more frequent occurrence of additional incisors in males than females of the polecat. More often existence of additional incisors in males was also proved by studies by Dolgov and Rossolimo (1964) in wolves, Bree and Sinkeldam (1969) in foxes, Glas (1977) and Wolsan (1993) in polecats. Also in the Polish population of the red fox, out of four cases of polidonties within incisors, three were found in males and one in an individual of undetermined sex. However, not all reports confirm more often occurrence of this feature in males. Berkovitz (1968) observed that in the deciduous dentition of ferrets additional incisors appeared in equal numbers in both sexes, whereas in the investigated by Wolsan (1984a) sample of the pine marten, females prevailed among the individuals with additional incisors.

Ruprecht (1978) proposed a hypothesis that the feature of additional incisors was genetically conditioned and related to sex. On the other hand, Wolsan (1984d) concludes that three different genetic mechanisms may decide about the appearance of additional incisors; viz. mutation, inclination to a definite recombination inducing polidonty within incisors, as well as the presence in the gene pool of the rare species genes responsible for the formation of the additional tooth in the incisor field.

I believe that the slightly more often $\left(p<0.05 ; \chi^{2}>1.00\right)$ occurrence of such irregularities as: polidonty, partial split of the crown, partial eruption and abnormalities in the arrangement of teeth in the dentition of males of the red fox are not genetically related to sex. All these kinds of irregularities, especially polidonties, require additional space in the row. It seems that assuming by fox males bigger dimensions of the body, and simultaneously of the skull, gives more possibilities for the appearance of additional teeth or rotations, or dislocations of teeth from their settled positions.

The dental irregularities observed in the red fox are deviations resulting from the operation of factors of both genetic and non-genetic nature. In the first group we can include mutations, disturbances of the genetic control during dental development and the existence in the species' gene pool of the occasionally manifesting their presence genes inherited from ancestors. The non-genetic basis of dental anomalies is created by viral and bacterial infections, mechanical injuries, shortages in the diet and stress, all happening during the tooth development. It seems that in most cases singular anomalies are results of a common and sometimes united operation of at least two different factors. 
Acknowledgements: I wish to thank the former head of the Institute of Systematics and Evolution of Animals PAS in Cracow, Prof K. Kowalski, for his agreement to lend me 494 fox skulls, and custodian G. Lipecki M.A. for giving me the run of his collection each time I needed. Moreover, I thank Ass. Prof M. Wolsan for his essential remarks during my writing of this paper and for the verification of the Polish version of the typescript. I thank Prof Z. Pucek and anonymous reviewers for their criticism. I am also grateful to Mr S. Buszko for preparing the photographs.

\section{References}

Ansorge H. 1993. Dentalverhältnisse des Rotfuchses Vulpes vulpes in der Oberlausitz. Beiträge zur Jagd- und Wildforschung 18: 71-78.

Asahi M. and Mori M. 1980. Abnormalities in the dentition of the racoondog, Nyctereutes procyonoides. Zoological Magazine 89: 61-64.

Batenan J. A. 1970. Supernumerary incisors in Mustelids. Mammal Review 1: 81-86.

Berkevitz B. K. B. 1968. Supernumerary deciduous incisors and the order of eruption of the incisor teeth in the albino ferret. Journal of Zoology, London 155: 445-449.

Berkevitz B. K. B. and Thomson P. 1973. Observations on the aetiology of supernumerary upper ircisors in the albino ferret (Mustela putorius). Archives of Oral Biology, London 18: 457-463.

Bittegeko S. B. P. R., Arnbjerg J., Nkya R. and Tevik A. 1995. Multiple dental developmental abnormalities following canine distemper infection. Journal of the American Animal Hospital Association 31: 42-45.

Bodirgbauer J. 1960. Retention of teeth in dogs as a sequel to distemper infection. The Veterinary Record 72: 636-638.

Bree P. J. H. van and Sinkeldam E. J. 1969. Anomalies in the dentition of the fox, Vulpes vulpes (Linnaeus, 1758) from continental western Europe. Bijdragen tot de Dierkunde 39: 3-5.

Buchilezyk T., Dynowski J. and Szteyn S. 1981. Variations in number of teeth and asymmetry of the stull in the wolf. Acta Theriologica 26: 23-30.

Cawson R. A. 1991. Essentials of dental surgery and pathology. Churchill Livingstone, Edinburgh, 1-321.

Dolgev V. A. and Rossolimo O. L. 1964. Dental abnormalities in Canis lupus Linnaeus, 1758. Acta Theriologica 8: 237-244. [In Russian with English summary]

Döcke F. 1959. Zahn- und Gebissanomalien beim Wild- und Farmfuchs. Archiv für Tierzucht 2: $150-161$.

Gawc J. 1995. Zarys stomatologii małych zwierząt. Sanmedia, Warszawa: 1-109.

Glas G. H. 1977. Numerical variation in the permanent dentition of the Polecat Mustela putorius (linnaeus), from Netherlands. Zeitschrift für Säugetierkunde 42: 256-259.

Glass G. E. and Todd N. B. 1977. Quasi-continuous variation of the second upper premolar in Felis bingalensis Kerr, 1792 and its significance for some fossil lynxes. Zeitschrift für Säugetierkunde 42 : 3i-44.

Glass.one S. 1952. The development of halved tooth germs. A study in experimental embryology. Jiurnal of Anatomy, London 86: 12-15.

Goodnan A. H., Armelagos G. J. and Rose J. C. 1980. Enamel hypoplasias as indicators of stress in three prehistoric populations from Illinois. Human Biology 52: 515-528.

Guilcay J. E. 1962. Supernumerary molars of Otocyon. Journal of Mammalogy 43: 455-462.

Herái I. 1987. On supernumerary roots in the permanent teeth of Carnivora. Věstnik Československé Sıolečnosti Zoologické 51: 125-128.

Hillsm S, 1986. Cambridge Manuals in archeology. Teeth. Cambridge University Press, Cambridge: 1-376.

Hitchin A. D. 1962. The radiology of the calcified composite odontomes. The Dental Practitioner 12: 2:3-240.

Hitchin A. D, 1971. The aetiology of the calcified composite odontomes. British Dental Journal 130: 45-482. 
Hitchin A. D. and Morris I. 1966. Geminated odontome - connation of the incisors in the dog - its etiology and ontogeny. Journal Dental Research 45, Suppl. 3: 575-583.

López-Peña M., Quiroga M. I., Vázquez S. and Nieto J. M. 1994. Detection of canine distemper viral antigen in foxes (Vulpes vulpes) in northwestern Spain. Journal of Wildlife Disease Association 30: 95-98.

Lüps P. 1974. Dreiwurzlige Praemolaren bei Rotfüchsen. Zeitschrift für Jagdwissenschaft 20: $163-165$.

Lüps P. 1990. Untersuchungen am P1 im Gebiss des europäischen Dasches (Meles meles). Zeitschrift für Säugetierkunde 55: 16-27.

Lüps P., Neuenschwander A. and Wandeler A. 1972. Gebissentwicklung und Gebissanomalien bei Füchsen (Vulpes vulpes L.) aus dem schweizerischen Mittelland. Revue Suisse de Zoologie 79: 1090-1103.

Łepkowski W. and Stach J. 1907. Przyczynek do poznania budowy zębiaków (odontomata). Przegląd Lekarski 1907: 1-17.

Miles A. E. W. 1954. Malformations of the teeth. Proceedings of the Royal Society of Medicine 47: 817-826.

Paradiso J. L. 1966. Notes on supernumerary and missing teeth in coyote. Mammalia 30: 120-128.

Pavlinov I. Ya. 1975. Tooth anomalies in some Canidae. Acta Theriologica 20: 507-519.

Rantanen A. V. and Pulliainen E. 1970. Dental conditions of wild red foxes (Vulpes vulpes L.) in northeastern Lapland. Annales Zoologici Fennici 7: 290-294.

Reinwaldt E. 1962. Über einige Anomalien im Gebiss des Rotfuchses, Vulpes vulpes vulpes Linné. Arkiv für Zoologi, Serie 2, 15: 371-375.

Robinson P. T. 1979. A literature review of dental pathology and aging by dental means in nondomestic animals - Part I and II. Journal of Zoology and Animal Medicine 10: 57-65, 81-91.

Ruprecht A. L. 1978. Dentition variations in the common polecat in Poland. Acta Theriologica 23: 213-238.

Szuma E. 1994. Quasi-continuous variation of the first premolars in the Polish population of the badger Meles meles. Acta Theriologica 39: 201-208.

Szuma E. 1997. Partial eruption of the teeth in the red fox. Acta Theriologica 42: 253-258.

Van Gelder R. G. and McLaughlin C. A. 1961. An unusual incisor in Mephitis mephitis. Journal of Mammalogy 42: 422-423.

Van Valen L. 1962. Growth fields in the dentition of Peromyscus. Evolution 16: 272-277.

Van Valen L. 1964. Nature of the supernumerary molars of Otocyon. Journal of Mammalogy 45: $284-286$.

Wolsan M. 1984a. Dental abnormalities in the pine marten Martes martes (L.) (Carnivora, Mustelidae) from Poland. Zoologische Anzeiger, Jena 213: 119-127.

Wolsan M. 1984b. Two dental anomalies in the Weasel (Mustela nivalis L.): A supernumerary premolar and a reduced upper molar (Mammalia, Carnivora, Mustelidae). Zoologische Abhandlungen Staatliches Museum für Tierkunde Dresden 40: 67-70.

Wolsan M. 1984c. Concerning the variation in the number, shape and size of incisors in fissiped carnivores. Acta Zoologica Cracoviensia 27: 107-120.

Wolsan M. 1984d. The origin of extra teeth in mammals. Acta Theriologica 29: 128-133.

Wolsan M. 1984e. An incisor with double crown in a Stoat (Mustela erminea L.). Zeitschrift für Säugetierkunde 49: 57.

Wolsan M. 1993. Mustela putorius Linnaeus, 1758 - Waldiltis, Europäischer Iltis, Iltis. [In: Handbuch der Säugetiere Europas. M. Stubbe and F. Krapp, eds]. Aula - Verlag, Wiesbaden Vol. 5: 699-769.

Received 3 December 1998, accepted 17 May 1999. 